\title{
Healthcare professionals' knowledge, attitudes, and practices regarding graduated compression stockings: a survey of China's big-data network
}

\author{
Yaping $X u^{1,2,3^{*}}$ (D) Wei Wang ${ }^{3}$, Kaiyuan Zhen ${ }^{4}$ and Jing Zhao ${ }^{3}$
}

\begin{abstract}
Background: The accurate identification of venous thromboembolism prophylaxis implementation barriers is an important part of prophylaxis prevention. However, in China, data to help identify these barriers is limited. This study has two objectives: 1) to determine the knowledge, attitudes, and practices (KAPs) of healthcare professionals regarding graduated compression stockings (GCS) since the launch of the National Program for the Prevention and Management of Pulmonary Embolism (PE) and Deep Venous Thrombosis (DVT) in October 2018 and 2) to identify the obstacles and assist the program.

Methods: This was a cross-sectional study of 5070 healthcare professionals in China. We used exploratory factor and reliability analyses to evaluate the researcher-designed questionnaire's reliability and validity. The formal questionnaire, which included demographic data, knowledge, attitudes, and clinical practice patterns, was distributed to healthcare professionals.

Results: Of the 5070 respondents, $32.5 \%$ had a good knowledge of GCS, $78.5 \%$ had a positive attitude towards their use, and 34.0\% exhibited normative behavior when applying them. The KAPs of healthcare professionals towards GCS were significantly correlated with one another. Binary logistic regression suggested that the training received by healthcare professionals was an important factor affecting their knowledge regarding GCS usage.

Conclusions: The training provided for the use of GCS in China cannot meet medical staff needs and deserves more attention from policy makers. This represents an obstacle for venous thromboembolism prophylaxis, which restricts the effective implementation of the National Program for Prevention and Management of PE and DVT.
\end{abstract}

Keywords: Graduated compression stockings, Venous thromboembolism, Knowledge, Attitude, Practice

\footnotetext{
* Correspondence: yaping0535@163.com

'Department of Orthopedics, China-Japan Friendship Hospital, 2 Yinghua Dongjie, Hepingli, Chaoyang District, Beijing 100029, China

${ }^{2}$ Bone Necrosis and Joint Preservation Reconstruction Center, China-Japan Friendship Hospital, Beijing, China

Full list of author information is available at the end of the article
}

C C The Author(s). 2020 Open Access This article is licensed under a Creative Commons Attribution 4.0 International License, which permits use, sharing, adaptation, distribution and reproduction in any medium or format, as long as you give appropriate credit to the original author(s) and the source, provide a link to the Creative Commons licence, and indicate if changes were made. The images or other third party material in this article are included in the article's Creative Commons licence, unless indicated otherwise in a credit line to the material. If material is not included in the article's Creative Commons licence and your intended use is not permitted by statutory regulation or exceeds the permitted use, you will need to obtain permission directly from the copyright holder. To view a copy of this licence, visit http://creativecommons.org/licenses/by/4.0/ The Creative Commons Public Domain Dedication waiver (http://creativecommons.org/publicdomain/zero/1.0/) applies to the data made available in this article, unless otherwise stated in a credit line to the data. 


\section{Background}

Venous thromboembolism (VTE) is the third-leading cause of cardiovascular-associated deaths worldwide [1]. Effective VTE prevention is an intense research area, and many guidelines [2-8] have been developed regarding VTE prophylaxis. Some studies suggest that the existence of a large real-world gap between Western evidence-based guidelines and the current knowledge of healthcare professionals represents an impediment to effective VTE prophylaxis implementation [9-13]. Accurately identifying the barriers to VTE prophylaxis implementation is an important part of VTE prevention. However, in China, data to help identify these VTE prophylaxis barriers is limited.

The National Program for the Prevention and Management of Pulmonary Embolism (PE) and Deep Venous Thrombosis (DVT) was launched in October 2018 in China. This program aims to improve the overall ability of hospitals to prevent, diagnose, and treat VTE. In this study, we aimed to determine the knowledge, attitude, and practices (KAPs) conducted by healthcare professionals regarding graduated compression stockings (GCS) since the launch of the National Program to identify obstacles and assist this program. To the best of our knowledge, our study is the first to explore the KAPs regarding the use of GCS by healthcare professionals accredited by the National Program and provide a basis for follow-up work.

\section{Methods}

\section{Study design}

This was a non-interventional, anonymized, selfadministered, one-time web-based survey for healthcare professionals in China. Based on the National Program for Prevention and Management of PE and DVT, this survey was conducted from November 19 to December $5,2019$.

\section{Survey questionnaire}

The questionnaire items were designed by experts from the working group for the National Program for Prevention and Management of PE and DVT. An original questionnaire that included 31 items was developed based on a preliminary survey of 928 cases to evaluate its reliability and validity. In the pre-investigation, researchers screened all items and created a formal questionnaire through exploratory factor analysis (EFA) using IBM SPSS Statistics for Windows version 25.0 (IBM Corp., Armonk, NY, USA). The questionnaire, which had a high Cronbach's alpha coefficient (0.952), was designed by experts from the National Program (Supplementary File 1). The 31-item validated questionnaire was used to collect demographic data (9 items), knowledge (11 items), attitude (4 items), and clinical practice patterns (7 items). The Cronbach's alpha for knowledge, attitude, and clinical practice pattern scales were 0.951, 0.910 , and 0.961 , respectively.

Demographical data included the following characteristics: gender, age, highest level of education attained, profession, hospital level, service years, professional title, administrative duties, and GCS usage training. The questionnaire did not ask for any personal identifying information. The other 22 items were single-choice questions, which were scored on a 5-point Likert scale ranging from 1 to 5 . The higher the score, the better the result.

The 11 items in the knowledge dimension were assessed using a 5-point Likert scale that was as follows: $1=$ very unfamiliar, $2=$ unfamiliar, 3 = generally familiar, $4=$ familiar, and $5=$ very familiar. Higher scores represented better knowledge. Further, the 4 items in the attitude dimension were evaluated as follows: $1=$ strongly disagree, 2 = disagree, 3 = generally agree, $4=$ agree, and $5=$ strongly agree. Higher scores indicated a more positive attitude. Finally, the 7 items in the clinical practice dimension were scored as follows: $1=$ never, $2=$ seldom, 3 = occasionally, $4=$ often, and $5=$ frequently. Higher scores represented a more normative behavior. Hence, a score of 4 and 5 points in any of the dimensions was considered good.

\section{Data collection}

This was a closed survey. The researchers uploaded the questionnaire to the Sojump online platform (https://www.wjx.cn/), which generated a QR code. The QR code was then distributed to the certifying agency's liaisons through the National Program's platform. The participants used the QR code through the WeChat application (Tencent Holdings, Shenzhen, China), and responded to and submitted the questionnaire.

The questionnaire was designed in such a way that it could not be submitted until all questions are answered. Participants could review and change their responses before submission. The survey period lasted for 18 days. During this time, 5070 healthcare professionals responded to the survey.

\section{Statistical analysis}

All data analyses were performed using IBM SPSS Statistics for Windows version 25.0 (IBM Corp., Armonk, NY, USA). Exploratory factor analysis and reliability analysis were used to evaluate the reliability and validity of this researcher-designed questionnaire. Descriptive statistical analysis was used to summarize the demographic characteristics of the 5070 healthcare professionals. Continuous data were expressed as means and standard deviations and were compared using Student's $t$-test. Categorical data were reported as absolute numbers and proportions and were compared using the Chi-Squared test. Pearson's 
correlation coefficients were computed to examine the relationship between the KAPs and GCS clinical usage. Binary logistic regression was used to analyze the factors that influenced the classification of "good" and "not good" for the knowledge dimension of healthcare professionals towards GCS clinical usage, and 95\% confidence intervals were calculated. A two-tailed $p$-value higher than 0.05 was considered statistically significant.

\section{Results}

\section{Demographic characteristics}

Demographic characteristics are shown in Table 1. Female medical staff represented the majority of respondents (91.0\%). Further, a major proportion of the

Table 1 Respondent characteristics ( $N=5070)$

\begin{tabular}{|c|c|c|c|}
\hline Characteristic & Categories & $n$ & $\%$ \\
\hline \multirow[t]{2}{*}{ Gender } & Men & 454 & 9.0 \\
\hline & Women & 4616 & 91.0 \\
\hline \multirow[t]{3}{*}{ Age (years) } & $<29$ & 1999 & 39.4 \\
\hline & $30-39$ & 2180 & 43.0 \\
\hline & $\geq 40$ & 891 & 17.6 \\
\hline \multirow[t]{5}{*}{ Highest education attained } & Secondary ${ }^{a}$ & 67 & 1.3 \\
\hline & College & 921 & 18.2 \\
\hline & Bachelor's degree & 3659 & 72.2 \\
\hline & Master's degree & 382 & 7.5 \\
\hline & Doctoral degree & 41 & 0.8 \\
\hline \multirow[t]{2}{*}{ Profession } & Doctor & 654 & 12.9 \\
\hline & Nurse & 4416 & 87.1 \\
\hline \multirow[t]{2}{*}{ Hospital level } & Tertiary hospital & 4523 & 89.2 \\
\hline & Secondary hospital & 547 & 10.8 \\
\hline \multirow[t]{4}{*}{ Service years } & $1-5$ & 1495 & 29.5 \\
\hline & $6-10$ & 1501 & 29.6 \\
\hline & $11-19$ & 1271 & 25.1 \\
\hline & $\geq 20$ & 803 & 15.8 \\
\hline \multirow[t]{3}{*}{ Professional title } & Junior & 2992 & 59.0 \\
\hline & Intermediate & 1688 & 33.3 \\
\hline & Senior & 390 & 7.7 \\
\hline \multirow[t]{4}{*}{ Administrative duties } & No & 4422 & 87.2 \\
\hline & Education secretary & 337 & 6.7 \\
\hline & Head nurse & 205 & 4.0 \\
\hline & Doctor director & 106 & 2.1 \\
\hline \multirow[t]{2}{*}{ GCS application training } & Yes & 3216 & 63.4 \\
\hline & No ${ }^{b}$ & 1854 & 36.6 \\
\hline
\end{tabular}

GCS Graduated compression stockings

${ }^{a}$ Even in some tertiary hospitals in China, there are a few nurses who have worked for more than 30 years who have only completed secondary education bIdeally, all healthcare professionals in hospitals accredited by the National Program for Prevention and Management of primary embolism and deep vein thrombosis should have training for the use of GCS; however, the survey shows a wide gap in the implementation of the program in the real world respondents had a bachelor's degree or a higher academic degree $(80.5 \%)$. Moreover, many of the respondents were nurses $(87.1 \%)$, most of whom worked in tertiary care hospitals $(89.2 \%)$, and $63.4 \%$ of respondents received GCS usage training.

\section{KAPs of healthcare professionals regarding GCS usage}

Figure 1 shows that of the 5070 respondents, 32.5\% had good knowledge regarding GCS usage; $78.5 \%$ had a positive attitude towards using GCS, and $34.0 \%$ exhibited normative behavior when using GCS. The proportions of "good" classifications for all the 22 KAP dimension items are illustrated in Fig. 2.

Table 2 indicates that the KAPs of healthcare professionals regarding clinical GCS usage significantly correlated with one another. There was a significantly positive, moderate correlation between knowledge and attitude $(r=0.463, p<0.01)$. Furthermore, there was a significantly positive strong correlation between knowledge and practice $(r=0.658, p<0.01)$, and a significantly positive moderate correlation between attitude and practice $(r=0.428, p<0.01)$.

\section{Factors from demographic characteristics that influenced} the "good" and "not good" classifications in the knowledge dimension

A single-factor analysis suggested that the independent variables that influenced the "good" and "not good" classifications in the knowledge dimension were statistically significant $(p<0.05 ; p<0.01)$ and included gender, age, hospital level, service years, administrative duties, and GCS usage training (Table 3). These variables were incorporated into a binary logistic regression model. Compared with men, women were less likely to have good knowledge regarding GCS clinical usage $(\mathrm{OR}=0.772$, 95\% CI 0.605-0.986) (Table 4). Moreover, compared with those who received GCS usage training, those who did not receive training had a very low probability of having good knowledge regarding GCS clinical usage $(\mathrm{OR}=0.097$, 95\% CI 0.081-0.117).

\section{Discussion}

\section{Current situation of the KAPs of healthcare professionals} regarding GCS clinical usage

A majority of the respondents reported a positive attitude towards GCS clinical usage. The lowest proportion of "good" classifications for the 11 items in the knowledge dimension and the 7 items in the practice dimension were 40.6 and $41.8 \%$, respectively, which was higher than that reported in previous surveys $[11,13]$. These results depended on the implementation of the National Program. Considering that all the participants in this survey were from hospitals accredited by the National Program, we expected a higher proportion of "good" 


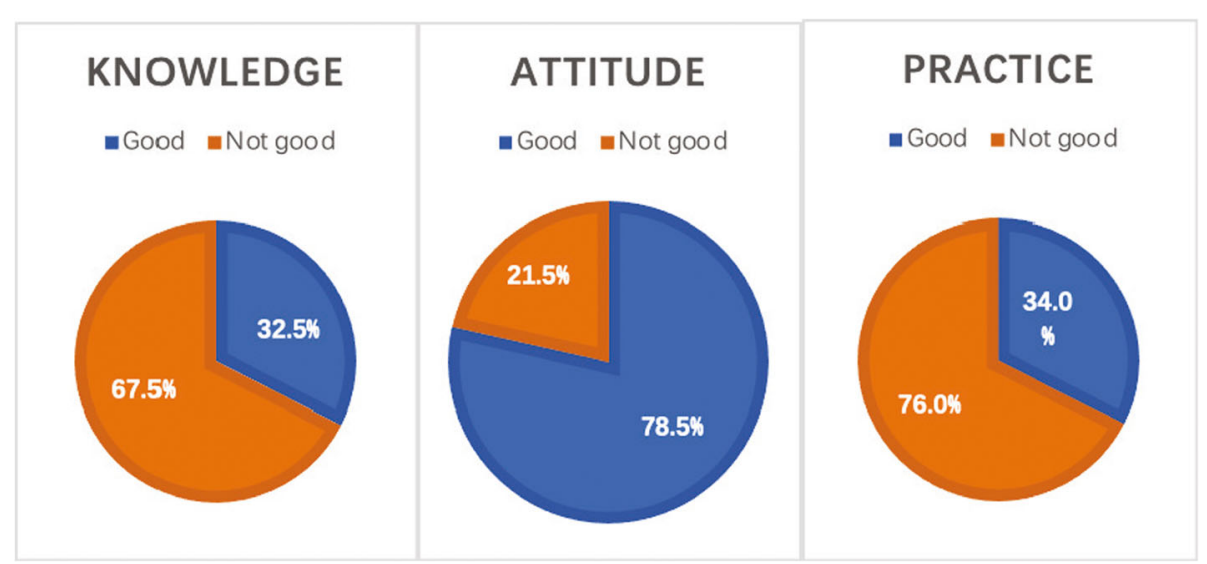

Fig. 1 Proportion of "good" classifications for KAP dimensions ( $N=5070)$

classifications for the knowledge and practice dimensions. A lower proportion may be suggestive of a substantial gap in the implementation of the program in the real world. Our survey indicates that the National Program should pay attention to the knowledge and practice dimensions in their future work. This result made the National Program members suspect that more detailed supervision and verification were necessary when the hospital was authorized. Simultaneously, providing uniform training courses to improve the work of the
National Program is necessary. Regular reviews of authorized hospitals are necessary in the future.

\section{Improve the knowledge of healthcare professionals regarding GCS clinical usage}

Our study shows that the KAPs of healthcare professionals regarding GCS clinical usage were significantly correlated with each other. Furthermore, although knowledge profoundness is particularly important, only

$$
\begin{aligned}
& 82.9-86.0-85.3-83.4
\end{aligned}
$$

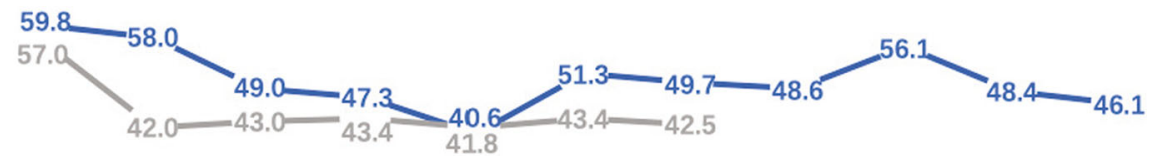

$$
\begin{aligned}
& \text { - - Knowledge - -Attitude - -Practice }
\end{aligned}
$$

$\begin{array}{lllllllllll}1 & 2 & 3 & 4 & 5 & 6 & 7 & 8 & 9 & 10 & 11\end{array}$

Fig. 2 Proportion of "good" classifications for the 22 KAP dimension items ( $N=5070$ ). Knowledge (11 items) 1. Mechanism of action; 2. Indications; .3. Contraindications; 4. Size; 5. Pressure level; 6. Length; 7. Timing; 8. Wearing method; 9. Maintenance instructions; 10 . Washing method; and 11. Service life. Attitude (4 items) 1. GCS benefits should be actively communicated to patients and their caregivers; 2 . Medical staff should teach patients and their caregivers the proper use of GCS; 3. Medical institutions and managers should pay attention to the training of healthcare professionals for GCS usage; and 4. GCS should be covered by Medicare. Practice (7 items) 1. I think my guidance on GCS usage for patients is in place; 2 I make sure that the patients in my charge have been well informed of GCS usage benefits; 3. I make sure that the patients in my charge are well aware of the importance of the proper use of GCS upon discharge; 4 . I make sure that the patients in my charge are capable of wearing GCS independently or with the help of the caregivers when they leave the hospital; 5 . I make sure that the patients under my charge know how to solve problems (such as skin indentation, blisters or discoloration) associated with GCS usage, especially at the ankle or protuberance, after discharge; 6 . I make sure that at discharge I have made clear to the patients in my charge who to contact in case of GCS misusage; and 7. I make sure that at discharge I have made it clear to the patients in my charge when to stop using GCS 
Table 2 KAP means, standard deviations, and Pearson's correlation coefficients ( $N=5070)$

\begin{tabular}{|c|c|c|c|c|c|c|c|}
\hline Variables & $M$ & $S D$ & Minimum & Maximum & Knowledge & Attitude & Behavior \\
\hline Knowledge & 38.18 & 9.098 & 11 & 55 & 1 & & \\
\hline Attitude & 16.65 & 2.656 & 4 & 20 & $0.463^{*}$ & 1 & \\
\hline Behavior & 22.22 & 8.227 & 7 & 35 & $0.658^{*}$ & $0.428^{*}$ & 1 \\
\hline
\end{tabular}

The correlation is significant at 0.01 (two-tailed)

$M$ Mean, SD Standard deviation

${ }^{*} p<0.01$

Table 3 Single-factor comparison of the demographic characteristics that influence "good" and "not good" classifications in the knowledge dimension

\begin{tabular}{|c|c|c|c|c|}
\hline & Good $(n=1647)$ & Not good $(n=3423)$ & $x^{2}$ & $P$ \\
\hline Gender, Men (\%) & $167(10.1)$ & $287(8.4)$ & $4.202^{a}$ & $0.040^{*}$ \\
\hline Age (years) & & & $26.331^{\mathrm{a}}$ & $0.000^{* *}$ \\
\hline$<29$ & $733(44.5)$ & $1266(37.0)$ & & \\
\hline $30-39$ & 649 (39.4) & $1531(44.7)$ & & \\
\hline$\geq 40$ & $265(16.1)$ & $626(18.3)$ & & \\
\hline Highest education attained & & & $5.955^{a}$ & 0.203 \\
\hline Secondary & $20(1.2)$ & $47(1.4)$ & & \\
\hline College & 279 (16.9) & $642(18.8)$ & & \\
\hline Bachelor's degree & $1217(73.9)$ & $2442(71.3)$ & & \\
\hline Master's degree & $114(6.9)$ & $268(7.8)$ & & \\
\hline Doctoral degree & $17(1.0)$ & $24(0.7)$ & & \\
\hline Profession & & & $0.159^{a}$ & 0.690 \\
\hline Doctor & 208 (12.6) & $446(13.0)$ & & \\
\hline Nurse & $1439(87.4)$ & $2977(87.0)$ & & \\
\hline Hospital level & & & $4.649^{\mathrm{a}}$ & $0.031^{*}$ \\
\hline Tertiary hospital & $1447(87.9)$ & 3076 (89.9) & & \\
\hline Secondary hospital & $200(12.1)$ & $347(10.1)$ & & \\
\hline Service years & & & $16.063^{\mathrm{a}}$ & $0.001^{* *}$ \\
\hline $1-5$ & $542(32.9)$ & $953(27.8)$ & & \\
\hline $6-10$ & $482(29.3)$ & 1019 (29.8) & & \\
\hline $11-19$ & $390(23.7)$ & $881(25.7)$ & & \\
\hline$\geq 20$ & $233(14.1)$ & $570(16.7)$ & & \\
\hline Professional title & & & $2.001^{\mathrm{a}}$ & 0.368 \\
\hline Junior & $995(60.4)$ & $1997(58.3)$ & & \\
\hline Intermediate & $531(32.2)$ & $1157(33.8)$ & & \\
\hline Senior & $121(7.3)$ & $269(7.9)$ & & \\
\hline Administrative duties & & & $12.664^{\mathrm{a}}$ & $0.005^{* *}$ \\
\hline No & $1420(86.2)$ & $3002(87.7)$ & & \\
\hline \multicolumn{5}{|l|}{ Education } \\
\hline Secretary & $130(7.9)$ & $207(6.0)$ & & \\
\hline Head nurse & $54(3.3)$ & $151(4.4)$ & & \\
\hline Doctor director & $43(2.6)$ & $63(1.8)$ & & \\
\hline GCS application training & & & $810.688^{a}$ & $0.000^{* *}$ \\
\hline Yes & $1502(91.2)$ & $1714(50.1)$ & & \\
\hline No & $145(8.8)$ & 1709 (49.9) & & \\
\hline
\end{tabular}

${ }^{\text {aPearson }}$ Chi-Square test

${ }^{*} p<0.05$; ** $p<0.01$ 
Table 4 The factors that influence "good" and "not good" classifications in the knowledge dimension in binary logistic regression analysis

\begin{tabular}{|c|c|c|}
\hline & 95\%Cl (Lower bound/upper bound) & $P$ \\
\hline Gender & & 0.038 \\
\hline Men & 1 & * \\
\hline Women & $0.772(0.605-0.986)$ & \\
\hline Age (years) & & 0.110 \\
\hline$<29$ & 1 & \\
\hline $30-39$ & $0.794(0.639-0.985)$ & \\
\hline$\geq 40$ & $0.764(0.487-1.198)$ & \\
\hline Hospital level & & 0.684 \\
\hline Tertiary hospital & 1 & \\
\hline Secondary hospital & $0.958(0.781-1.176)$ & \\
\hline Service years & & 0.668 \\
\hline $1-5$ & 1 & \\
\hline $6-10$ & $0.983(0.805-1.201)$ & \\
\hline $11-19$ & $0.958(0.730-1.256)$ & \\
\hline$\geq 20$ & $0.748(0.462-1.211)$ & \\
\hline Administrative duties & & 0.050 \\
\hline No & 1 & \\
\hline Education secretary & $1.253(0.962-1.633)$ & \\
\hline Head nurse & $0.806(0.570-1.140)$ & \\
\hline Doctor director & $1.602(0.992-2.586)$ & \\
\hline GCS application training & & $0.000^{* *}$ \\
\hline Yes & 1 & \\
\hline No & $0.097(0.081-0.117)$ & \\
\hline
\end{tabular}

$32.5 \%$ of the respondents had good knowledge regarding GCS usage, which was not encouraging. The National Program team recommends that the knowledge of healthcare professionals regarding GCS usage must include the following: action mechanism, indications, contraindications, sizes, pressure levels, lengths, usage timing, wearing methods, maintenance instructions, washing methods, and service life. These recommendations are consistent with the views of other scholars [14-16].

\section{Focus on GCS usage training}

A single-factor analysis and binary logistic regression model have suggested that the important factors from the demographic characteristics that may influence "good" and "not good" classifications in the knowledge dimension were gender and training for GCS usage. Our study indicates that men were more likely to have a good knowledge regarding clinical GCS usage compared with women, and participants who received training on GCS usage had a much higher probability of having good knowledge of its use compared with those who did not receive training. Hence, we believe that the National Program should focus on training to make better use of GCS.

Our study has some limitations. First, participants were from hospitals accredited by the National Program. Their response to the survey was voluntary and not mandatory through the National Program. This study did not investigate the proportion of respondents in the authorized hospital, and the researchers hoped that participants would participate in this survey in a relaxed state. Based on these considerations, our results were likely to be better than those of Chinese studies as a whole. However, this study can still provide a basis for the future work of the National Program to a large extent. In the follow-up study, a cluster sampling survey can be carried out for authorized tertiary hospitals to reflect the current situation more objectively. Second, many of the respondents were nurses (87.1\%), most of whom worked in tertiary hospitals $(89.2 \%)$. China is a developing country with an uneven distribution of 
medical resources. Generally speaking, medical personnel with high-level knowledge are concentrated in tertiary hospitals. As such, we are concerned about secondary and community hospitals. Hence, the project team faces great work challenges and more doctors are needed to be involved in future research. In addition, a larger study sample is required.

\section{Conclusions}

The knowledge of healthcare professionals regarding GCS clinical usage is not profound, and this represents a barrier for VTE prophylaxis in China. Training for the proper use of GCS in China has not yet met medical staff needs and deserves primary attention from policy makers. The substantial gap in the implementation of the program in the real world may be overcame by gaining the attention of practitioners as well as that of hospital management, which may result in the enhancement of medical education and management regarding GCS clinical usage.

\section{Supplementary Information}

The online version contains supplementary material available at https://doi. org/10.1186/s12913-020-05933-9.

\section{Additional file 1.}

\section{Abbreviations}

DVT: Deep venous thrombosis; GCS: Graduated compression stockings; PE: Pulmonary embolism; VTE: Venous thromboembolism

\section{Acknowledgments}

The authors would like to acknowledge the National Program for Prevention and Management of Pulmonary Embolism and Deep Venous Thrombosis and all study participants.

\section{Authors' contributions}

YPX and JZ contributed to the study concept and design. YPX, WW and KYZ coordinated the sampling and data collection. YPX and KYZ contributed to the data analysis. YPX contributed in writing the manuscript. YPX and JZ contributed to the critical review of the manuscript. All authors approved the final manuscript.

\section{Funding}

This research received no specific grant from any funding agency in the public, commercial or not-for-profit sectors.

\section{Availability of data and materials}

The datasets generated and/or analyzed during the current study are not publicly available because they are anonymized, though they are available from the corresponding author on reasonable request.

\section{Ethics approval and consent to participate}

The study was approved by the institutional review board of the ChinaJapan Friendship Hospital and adhered to the Helsinki Declaration. Written informed consent was not required because the questionnaire was anonymous and characterized by a less-than-minimal risk of privacy invasion.

\section{Consent for publication}

Not applicable.

\section{Competing interests}

The authors declare that they have no competing interests.

\section{Author details}

'Department of Orthopedics, China-Japan Friendship Hospital, 2 Yinghua Dongjie, Hepingli, Chaoyang District, Beijing 100029, China. ${ }^{2}$ Bone Necrosis and Joint Preservation Reconstruction Center, China-Japan Friendship Hospital, Beijing, China. ${ }^{3}$ Department of Nursing, China-Japan Friendship Hospital, Beijing, China. ${ }^{4}$ Institute of Clinical Medical Sciences, China-Japan Friendship Hospital, Beijing, China.

Received: 28 May 2020 Accepted: 17 November 2020

Published online: 25 November 2020

\section{References}

1. Mackman N. Triggers, targets and treatments for thrombosis. Nature. 2008; 451:914-8.

2. Kahn SR, Lim W, Dunn AS, Cushman M, Dentali F, Akl EA, et al. Prevention of VTE in nonsurgical patients: antithrombotic therapy and prevention of thrombosis, 9th Ed: American College of Chest Physicians Evidence-Based Clinical Practice Guidelines. Chest. 2012;141:e195S-226S.

3. Lansberg MG, O'Donnell MJ, Khatri P, Lang ES, Nguyen-Huynh MN, Schwartz $\mathrm{NE}$, et al. Antithrombotic and thrombolytic therapy for ischemic stroke: antithrombotic therapy and prevention of thrombosis, 9th Ed: American College of Chest Physicians Evidence-Based Clinical Practice Guidelines. Chest. 2012;141:e601S-36S

4. Dennis M, Caso V, Kappelle LJ, Pavlovic A, Sandercock P. European stroke organisation. European stroke organisation (ESO) guidelines for prophylaxis for venous thromboembolism in immobile patients with acute ischaemic stroke. Eur Stroke J. 2016;1:6-19.

5. Kearon C, Akl EA, Ornelas J, Blaivas A, Jimenez D, Bounameaux H, et al. Antithrombotic therapy for VTE disease: CHEST guideline and expert panel report. Chest. 2016;149:315-52.

6. Chinese Orthopaedic Association. Prevention of venous thromboembolism after major orthopaedic surgery (in Chinese). Orthop Surg. 2010;2:81-5.

7. Schünemann HJ, Cushman M, Burnett AE, Kahn SR, Beyer-Westendorf J, Spencer FA, et al. American Society of Hematology 2018 guidelines for management of venous thromboembolism: prophylaxis for hospitalized and nonhospitalized medical patients. Blood Adv. 2018;2:3198-225.

8. Anderson DR, Morgano GP, Bennett C, Dentali F, Francis CW, Garcia DA, et al. American Society of Hematology 2019 guidelines for management of venous thromboembolism: prevention of venous thromboembolism in surgical hospitalized patients. Blood Adv. 2019;3:3898-944.

9. Al-Dorzi HM, Cherfan A, Al-Harbi S, Al-Askar Hroub A, et al. Knowledge of thromboprophylaxis guidelines pre- and post-didactic lectures during a venous thromboembolism awareness day at a tertiary-care hospital. Ann Thorac Med. 2013:8:165-9.

10. McFarland L, Ward A, Greenfield S, Murray E, Heneghan C, Harrison S, et al. ExPeKT_exploring prevention and knowledge of venous thromboembolism: a two-stage, mixed-method study protocol. BMJ Open. 2013;3:e002766.

11. Tang $X$, Sun $B$, Yang $Y$, Tong $Z$. A survey of the knowledge of venous thromboembolism prophylaxis among the medical staff of intensive care units in North China. PLoS One. 2015;10:e0139162.

12. Ma Y-F, Xu Y, Chen Y-P, Wang X-J, Deng H-B, He Y, et al. Nurses' objective knowledge regarding venous thromboembolism prophylaxis: a national survey study. Medicine (Baltimore). 2018;97:e0338.

13. Xu Y, Wang W, Zhao J, Wang J, Zhao T. Knowledge, attitude, and practice of healthcare professionals toward clinically applying graduated compression stockings: results of a Chinese web-based survey. J Thromb Thrombolysis. 2019;47:102-8.

14. Lim CS, Davies AH. Graduated compression stockings. CMAJ. 2014;186:E391-8.

15. Wang H, Fang HP, Liu HJ, Cai C, Liu J. The research progress of graduated compression stockings in deep vein thrombosis. Chinese Nurs Manag. 2017; 17:1458-63.

16. Professional Committee on Nursing Care, Chinese Chapter of International Union of Angiology; The Society of Endovascology, Chinese Medical Doctor Association. Expert consensus on the application of graduated compression stockings for prevention and treatment of venous thromboembolism. J Intervent Radiol. 2019;28:811-8.

\section{Publisher's Note}

Springer Nature remains neutral with regard to jurisdictional claims in published maps and institutional affiliations. 